\title{
Efficiency of feed use by broiler chickens of the "Cobb-500" cross when feeding a probiotic preparation
}

\author{
Ivan Koschayev ${ }^{1 *}$, Christina Mezinova ${ }^{1}$, Nadezhda Sorokina ${ }^{1}$, Antonina Ryadinskaya ${ }^{1}$, \\ Natalia Ordina ${ }^{1}$, and Sergey Chuyev $^{1}$ \\ ${ }^{1}$ Belgorod State Agricultural University, 1, Vavilova str., Maisky, 308503, Belgorod region, Belgorod \\ oblast, Russia
}

\begin{abstract}
One of the methods of combating unwanted microflora is the use of antibiotics, however, along with positive properties, they have a number of significant disadvantages, in particular, the detrimental effect of both pathogenic and beneficial intestinal microflora. In this regard, there is an urgent need to replace antibiotics with safer substances, which increasingly include probiotics. The mechanism of action of probiotics is to selectively affect pathogenic microflora, without harming the beneficial one. In the course of the study, it was found that low-protein diets (low in protein, but balanced in amino acid profile) allow unlocking the potential of probiotic cultures of the Bacillus amyloliquefaciens strain and, as a result, reduce feed conversion by $0.08 \mathrm{~kg} / \mathrm{kg}$.
\end{abstract}

\section{Introduction}

Poultry farming in most developed countries of the world occupies one of the leading positions in agriculture, supplying the population with dietary food products of high value, and processing enterprises with raw materials $[1,2,3]$.

At this stage of the development of industrial poultry farming, exclusively highly productive poultry crosses are used, the genetically determined productivity potential of which can be realized through the introduction of new technologies that reduce production costs, increase the viability and productivity of livestock, as well as a decrease in feed conversion $[4,5]$.

Highly productive poultry, which includes almost all modern crosses of broiler chickens, is characterized by an increased intensity of metabolic processes in the body and high productivity, and more sensitive to various stressful situations.

In a relatively short rearing period, broiler chickens increase their live weight by 50-60 times. This is ensured by the intensification of the activity of all organs and organ systems, which are associated with the protective functions of the body. An increase in metabolic processes in highly productive poultry (broiler chickens) is accompanied by a decrease in the body's resistance to even minor changes in environmental factors. This conclusion is

\footnotetext{
*Corresponding author: koshchaev@,yandex.ru
} 
confirmed by the frequent manifestation of diseases caused by pathogenic and opportunistic pathogens and a general decrease in the body's resistance [6].

The components that make up the compound feed actively affect the state of the gastrointestinal tract of animals. Feeding broilers without scientific basis can lead to changes in the microbiocenosis, lead to the appearance of diseases and reduce the productivity of poultry. In addition, studies by many scientists show that intestinal microbiocenosis is capable of exhibiting a protective function and exerting a preventive effect on the colonization of the intestine by pathogenic microorganisms [7].

An important component of ensuring a stable mechanism for growing and obtaining environmentally friendly products is the search for alternative growth stimulants, in particular the use of probiotic preparations for industrial poultry farming $[8,9]$.

Substances that can replace feed antibiotics in their action are relevant in poultry feeding. Many manufacturers are reluctant to use antibiotics because they do not protect the product from bacteria that are resistant to their action. On the other hand, there is evidence that not only sweat and opportunistic microorganisms, but also largely feed antibiotics inhibit the growth and activity of beneficial bacteria in the intestines of poultry. Therefore, instead of feed antibiotics, biologically active preparations, characterized as probiotics, are entering the Russian and world markets. They have a different composition, different quality characteristics, different pharmacological focus. The successful use of probiotic preparations, which can be carried out by feeding with food, drinking with water, and other methods, has been noted by many researchers. There is evidence of the use of these substances, for prophylactic and therapeutic purposes, from diseases of the digestive tract. Violations can occur with a sharp change in the composition of the feed, as well as in violation of the feeding technology and stressful situations when raising poultry. On the other hand, the positive effect of replacing feed antibiotics with them is indicated, which is manifested in improved utilization of feed nutrients and stimulation of the growth of animals and birds [10].

The action of probiotic preparations is based on the competitive interaction of putrefactive microorganisms and opportunistic microorganisms of the gastrointestinal tract, which contributes to an increase in the population of useful microflora, thereby increasing the percentage of digestibility of feed nutrients by activating metabolic processes [11].

The scientific literature contains data on the successful use of probiotic preparations in animal husbandry in order to increase the body's resistance, correct digestive tract dysbacteriosis, increase the efficiency of feed use, and stimulate the growth and productivity of livestock. The positive effect of probiotics on the body is also explained by the fact that they stimulate the growth of its own microflora. Based on this, the ultimate goal of taking probiotics is to restore the animal's own microflora [12].

As probiotics, modern researchers recommend the use of preparations based on bifidobacteria (Bifidum adolescentis, Bifidum bifidum, Bifidum langum, Bifidum globosum, Bifidum thermophilus and others); lactic acid bacteria (lactobacilli): Lactobacillus acidophilus, Lactobacillus planlarum, Lactobacillus casei, Lactobacillus fermentum, Lactobacillus bulgaricus, Lactobacillus rhamnosus, Lactobacillus acidophilus and others); spore-forming bacteria of the genus Bacillus (Bacillus subtilis, Bacillus licheniformis, Bacillus cereus, Bacillus amyloliquefaciens, Bacillus panthothenticus, Bacillus brevis, Bacillus laterosporus, Bacillus cereus, and others) [13].

The main factor determining the effectiveness of the probiotic is the strain [14]

In addition, probiotic preparations have a number of advantages over other biologically active additives as they have: better digestibility and assimilation of nutrients due to high proteinase and lipase activity; the ability to reduce the lactose content, which makes it possible to use them for hypolactasia; the best stimulating effect on the secretory function of the digestive glands; the ability to normalize the composition of the microflora of the gastrointestinal tract and improve intestinal motility due to the presence of lactic acid; better 
optimization of absorption in the small intestine of macro- and microelements; the ability to provide a hypocholesterol effect and an immunomodulatory effect on the body; good sorption properties, allowing you to remove various toxicants from the body [15].

The use of probiotics in poultry feeding is based on the fact that normal microflora is involved in maintaining the resistance of the intestinal mucosa, which in turn plays an important role in the prevention of poultry diseases. Thus, the study of the influence of probiotic crops on the mechanisms of growth and development of poultry does not lose its relevance, since numerous studies have proven that the inclusion of probiotics in the system of growing broiler chickens reduces the incidence of gastrointestinal diseases, reduces the duration of growing, reduces feed costs and increases safety. Probiotics improve the slaughter and meat qualities of poultry and the long-term use of probiotics both in our country and abroad suggests that probiotic preparations should be considered as an integral component of rational poultry feeding. [16]. In the course of our earlier study, it was found that low-protein diets allow unlocking the potential of probiotic cultures of the amyloliquefaciens strain and, as a result, increase the safety of broiler chickens by $4.6 \%$, live weight by $10.1 \%$.

\section{Materials and methods}

Studies to study the effect of probiotic cultures of the Bacillus amyloliquefaciens strain on reducing feed conversion were carried out on Cobb-500 broilers under the conditions of the educational and scientific poultry farm of Belgorod State Agrarian University.

To conduct scientific and economic experience, 4 groups were formed - control and 3 experimental. For this, from a batch of 2340 broiler chickens, 36 sections of 65 heads in each were selected, 9 sections (replicates) for each experimental group. Day-old chickens were randomly assigned to 36 cages. During the experimental period, 4 different diets were studied for 40 days.

The chickens of the control and experimental groups were given the same conditions of keeping, feeding and drinking, corresponding to the normative indicators. The chicken feeding and watering system is automated and the equipment of the Big Dutchman Company is used. Distribution of feed does not depend on the time of day, it is carried out constantly.

Features of feeding broiler chickens were as follows (table 1):

1 - The control group received a standard diet;

2 - The experimental group received low protein ratsиoн;

3 - The experimental group received a standard diet + probiotic Bacillus amyloliquefaciens;

4 - The experimental group received a low-protein diet + probiotic Bacillus amyloliquefaciens.

In experimental groups 2 and 4 (Low-protein diet), synthetic amino acids L-Valine, LIsoleucine and L-arginine were additionally introduced in the rations GROWER and FINISHER. The reduction in the crude protein of the feed in groups 2 and 4 will be about $1.5-2 \%$ for each phase.

In the conditions of intensive meat poultry farming, control over the physiological state, the development of young poultry and taking into account all the costs of industrial products is of great importance. Therefore, with the further improvement of broiler growing technologies, the focus should be on a careful attitude to the consumption of feed, as well as the study of all factors that affect unjustified losses of feed and products.

During the experiment, the following indicators were determined:

- microclimate data in the poultry house (daily) (temperature, humidity, ventilation parameters in $\mathrm{m} 3 / \mathrm{h}$ per head, illumination);

- feed distribution accounting (daily); 
Table 1. Scheme of the experience by the distribution of groups in the experimental building.

\begin{tabular}{|c|c|c|c|}
\hline \multicolumn{4}{|c|}{ Diets/groups } \\
\hline $\mathbf{1 1}$ & T2 & T3 & T4 \\
\hline $\mathbf{1 2}$ & 21 & $\mathbf{3 1}$ & 41 \\
\hline $\mathbf{1 3}$ & 23 & $\mathbf{3 3}$ & 43 \\
\hline $\mathbf{1 4}$ & 24 & $\mathbf{3 4}$ & 44 \\
\hline $\mathbf{1 5}$ & 25 & $\mathbf{3 5}$ & 45 \\
\hline $\mathbf{1 6}$ & 26 & $\mathbf{3 6}$ & 46 \\
\hline $\mathbf{1 7}$ & 27 & $\mathbf{3 7}$ & 47 \\
\hline $\mathbf{1 8}$ & 28 & $\mathbf{3 8}$ & 48 \\
\hline $\mathbf{1 9}$ & 29 & $\mathbf{3 9}$ & 49 \\
\hline
\end{tabular}

- body weight by weighing at the age - 0 (1) day, 10th day, 23rd day, 40th day; per phase.

- calculation of feed consumption, feed conversion, $\%$ waste for the period was calculated immediately after weighing;

\section{Results}

The indicator of feed consumption per unit of gain is important from an economic point of view. This is one of the most important indicators of choosing the optimal feeding and breeding program.

The optimal diet is made taking into account the need for nutrients per unit of gain in live weight, corresponding to a certain segment of the growth curve. With an increase in weight, the animal's need for food to maintain life also changes. At the same time, the feed cost indicator also characterizes the difference in the synthesis of proteins and fats, that is, all complex changes in metabolism are reflected in the changes in feed costs for live weight gain.

Nutrients consumed with feed are initially consumed to maintain the vital processes of the broiler organism, and subsequently to increase live weight. With an increase in the live weight of broilers and the growing period, both of these indicators increase, so the task is to achieve the planned target live weight in a shorter time. Broiler poultry farming is based on the feeding of highly productive poultry crosses, providing at 5-6 weeks of age, on average, a live weight of 2.0-2.5 kg, with a cost of $1.76-1.9 \mathrm{~kg}$ of feed, per $1 \mathrm{~kg}$ of gain.

In the course of the study, it was found that the probiotic preparation of the Bacillus amyloliquefaciens strain under study has a positive effect on the transition of feed into products.

The increase in live weight of the birds of the compared groups was observed based on the results of individual control weighing. At the same time, taking into account the data of the absolute increase in the mass of the experimental groups, the consumption of compound feed was calculated per $1 \mathrm{~kg}$ of the produced product (table 2). 
Table 2. Accounting for live weight and feed conversion of broiler chickens of the "Cobb-500" cross when using a probiotic strain of Bacillus amyloliquefaciens, $\mathrm{g}, \mathrm{kg} / \mathrm{kg}$.

\begin{tabular}{|c|c|c|c|c|c|c|c|c|c|c|c|}
\hline Diet & & \multicolumn{9}{|c|}{ Live weight by groups } & \multirow[t]{2}{*}{ Average } \\
\hline \multirow[t]{5}{*}{ T1 } & $\begin{array}{l}\text { Age, } \\
\text { days }\end{array}$ & 11 & 12 & 13 & 14 & 15 & 16 & 17 & 18 & 19 & \\
\hline & 1 & 49.9 & 50.3 & 50.2 & 50.5 & 50.4 & 49.8 & 50.6 & 50.4 & 50.2 & 50.2 \\
\hline & 40 (av.) & 2380 & 2364 & 2408 & 2393 & 2356 & 2378 & 2366 & 2415 & 2396 & 2383.9 \\
\hline & \multicolumn{11}{|c|}{ Feed conversion, $\mathrm{kg} / \mathrm{kg}$} \\
\hline & & 1.82 & 1.76 & 1.86 & 1.87 & 1.86 & 1.79 & 1.69 & 1.87 & 1.76 & 1.81 \\
\hline \multirow[t]{5}{*}{ T2 } & $\begin{array}{l}\text { Age, } \\
\text { days }\end{array}$ & 21 & 22 & 23 & 24 & 25 & 26 & 27 & 28 & 29 & \\
\hline & 1 & 50.1 & 50.7 & 50.4 & 50.0 & 50.5 & 50.1 & 50.6 & 50.0 & 50.3 & 50.3 \\
\hline & 40 (av.) & 2483 & 2539 & 2554 & 2534 & 2528 & 2589 & 2548 & 2486 & 2500 & 2540.2 \\
\hline & \multicolumn{11}{|c|}{ Feed conversion, $\mathrm{kg} / \mathrm{kg}$} \\
\hline & & 1.75 & 1.76 & 1.78 & 1.65 & 1.75 & 1.77 & 1.63 & 1.75 & 1.80 & 1.74 \\
\hline \multirow[t]{5}{*}{ T3 } & $\begin{array}{l}\text { Age, } \\
\text { days }\end{array}$ & 31 & 32 & 33 & 34 & 35 & 36 & 37 & 38 & 39 & \\
\hline & 1 & 50.4 & 50.4 & 50.2 & 50.1 & 50.0 & 49.6 & 50.2 & 50.6 & 49.6 & 50.1 \\
\hline & 40 (av.) & 2456 & 2422 & 2402 & 2433 & 2395 & 2475 & 2437 & 2375 & 2442 & 2426.3 \\
\hline & \multicolumn{11}{|c|}{ Feed conversion, $\mathrm{kg} / \mathrm{kg}$} \\
\hline & & 1.71 & 1.80 & 1.72 & 1.69 & 1.70 & 1.64 & 1.66 & 1.68 & 1.68 & 1.70 \\
\hline \multirow[t]{5}{*}{ T4 } & $\begin{array}{l}\text { Age, } \\
\text { days }\end{array}$ & 41 & 42 & 43 & 44 & 45 & 46 & 47 & 48 & 49 & \\
\hline & 1 & 49.8 & 50.3 & 50.5 & 50.4 & 50.3 & 50.2 & 50.6 & 50.4 & 50.2 & 50.3 \\
\hline & 40 (av.) & 2590 & 2589 & 2647 & 2609 & 2616 & 2661 & 2658 & 2613 & 2640 & 2624.7 \\
\hline & \multicolumn{11}{|c|}{ Feed conversion, $\mathrm{kg} / \mathrm{kg}$} \\
\hline & & 1.64 & 1.72 & 1.65 & 1.60 & 1.68 & 1.68 & 1.65 & 1.67 & 1.63 & 1.66 \\
\hline
\end{tabular}

The results of the scientific and economic experiment indicate that feeding a probiotic preparation of the Bacillus amyloliquefaciens strain as part of a complete mixed feed had a positive effect on the growth of broiler chickens in the experimental groups. This is manifested in a more intensive growth of the livestock, due to which, by the end of the cultivation, the broilers of the experimental groups had a large final weight.

Thus, the chickens receiving the standard diet + probiotic Bacillus amyloliquefaciens by the end of growing outnumbered the group receiving the standard diet by $1.8 \%$, respectively.

Chickens fed a low-protein diet + probiotic Bacillus amyloliquefaciens by the end of rearing outnumbered the group receiving a low-protein diet by $3.3 \%$, respectively.

As a result of the study, it was found that the introduction of the probiotic additives under study into the composition of mixed fodders had a positive effect on payment for fodder with products, and also contributed to a decrease in fodder consumption per $1 \mathrm{~kg}$ of live weight gain.

After analyzing the data in Table 2, we can conclude that the bird of the 4th experimental group used the feed most effectively. The bird of the 2 nd group is somewhat worse.

Chickens of the 1st and 3rd groups used feed least effectively.

In chickens fed with the standard diet + probiotic Bacillus amyloliquefaciens, the feed conversion decreased relative to the group fed with the standard diet by $0.11 \mathrm{~kg} / \mathrm{kg}$.

In chickens fed a low-protein diet + probiotic Bacillus amyloliquefaciens, feed conversion decreased in relation to the group receiving a low-protein diet by $0.08 \mathrm{~kg} / \mathrm{kg}$, respectively.

\section{Conclusion}

As follows from the results obtained, the probiotic preparation we used based on Bacillus amyloliquefaciens unambiguously influenced the growth and development of the 
experimental bird, as well as a decrease in feed conversion. Summarizing the obtained material, we developed a working hypothesis, according to which it is advisable to introduce a probiotic preparation based on Bacillus amyloliquefaciens into the diet in the production of broiler meat and improve their quality.

\section{References}

1. S. Zdanovich, International Transaction Journal of Engineering, Management, \& Applied Sciences \& Technologies, 11 (14) (2020)

2. I. Miroshnichenko, Utilization, and Environmental Effects, Part A (2020)

3. A. Ryadinskaya, materials BIO Web of Conferences, 27, 00059 (2020)

4. O. Yastrebova, Advances in Biological Sciences Research 1st International Symposium Innovations in Life Sciences (ISILS 2019), 7, 361-364(2019)

5. A. Fedosova, Foods and Raw Materials, 5, 44-53 (2017)

6. A. Kovrigin, Advances in Biological Sciences Research 1st International Symposium Innovations in Life Sciences (ISILS 2019), 7, 175-178 (2019)

7. I. Koshchaev, Web Conf. Innovative Technologies in Science and Education (ITSE2020) 210 (2020)

8. N. Shvetsov, Advances in Biological Sciences Research 1st International Symposium Inno-vations in Life Sciences (ISILS 2019), 7, 280-283 (2019).

9. A. Dobudko, Journal of Pharmaceutical, Biological and Chemical Sciences, 9 (6), 15511559 (2018)

10. I. Koshchaev, E3S Web Conf. Innovative Technologies in Science and Education, 210 (2020)

11. A. Fedosova, Research Journal of Pharmaceutical, Biological and Chemical Sciences, 9 (5), 950-959 (2018)

12. I. Koschayev, Advances in Biological Sciences Research 1st International Symposium Innovations in Life Sciences (ISILS 2019), 7, 167-170 (2019)

13. G. Pokhodnya, Research Journal of Pharmaceutical, Biological and Chemical Sciences, 9 (5), 2281-2291 (2018)

14. N. Ordina, Advances in Biological Sciences Research 1st International Symposium Innovations in Life Sciences (ISILS 2019), 7, 235-239 (2019)

15. Z. Gao, Animal Nutrition, 2, 109-113 (2017)

16. A. Shaposhnikov, Research Result: Pharmacology and Clinical Pharmacology, 4, 91-94 (2016) 